\title{
As políticas de formação contínua de professores no estado de São Paulo: debatendo perspectivas de transformação a partir da pedagogia progressista freireana
}

\author{
Policies of teachers' continuing education in \\ the state of São Paulo: debating transformation \\ perspectives from the Freirean progressive \\ pedagogy
}

\section{Las políticas de formación continua de profesores en el estado de São Paulo: debatiendo perspectivas de transformación a partir de la pedagogía progresiva freireana}

Lucimara Cristina de Paula* Roseli Rodrigues de Mello*

\begin{abstract}
Resumo: Este texto apresenta discussões sobre a formação contínua de professores dos anos iniciais do Ensino Fundamental, a partir de um olhar crítico sobre as políticas de formação, implementadas pelo governo do estado de São Paulo. Essas discussões fazem parte de uma pesquisa de doutorado, cujo objetivo principal foi verificar o potencial teórico-metodológico da práxis freireana para a construção de conhecimentos orientados à transformação das pesquisas e das propostas sobre a formação dos professores e de seus formadores. A metodologia contou com relatos biográficos, que foram analisados mediante os pressupostos da Metodologia Comunicativo-crítica e da Pedagogia Progressista de Paulo Freire. Os resultados da pesquisa apontam contribuições à formação contínua de educadores dentro e fora dos espaços escolares. Palavras-chave: Formação contínua de professores. Políticas de formação contínua. Paulo Freire.
\end{abstract}

Abstract: This text presents discussions on the continuing education of teachers of the early years of Elementary School, from a critical point of view on education policies, implemented by the government of the state of São Paulo, Brazil. These discussions

\footnotetext{
*Professora da Universidade Estadual de Ponta Grossa (UEPG). E-mail: <lucrispaula@gmail.com>

** Professora da Universidade Federal de São Carlos (UFSCar). Coordenadora do Núcleo de Investigação e Ação Social e Educativa - NIASE e bolsista produtividade CNPq. E-mail: <roseli@ufscar.br>
} 
are part of a doctoral research whose primary purpose was to verify the theoreticalmethodological potential of freirean praxis for the construction of knowledge oriented to the transformation of researches and proposals on the education of teachers and their educators. The methodology included biographical accounts, which were analyzed through the Critical-Communicative Methodology assumptions and Paulo Freire's Progressive Pedagogy. The research results indicate contributions to the education of educators inside and outside of school spaces.

Keywords: Continuing teacher education. Continuing education policies. Paulo Freire.

Resumen: Este texto presenta discusiones sobre la formación continua de maestros de los años iniciales de la Enseñanza Primaria, a partir de una mirada crítica sobre las políticas de formación, implementadas por el gobierno del estado de São Paulo. Estas discusiones hacen parte de una pesquisa de doctorado, cuya meta principal fue verificar el potencial teórico-metodológico de la praxis freireana para la construcción de conocimientos orientados a la transformación de las pesquisas y propuestas sobre la formación de los maestros y de sus instructores. La metodología contó con informes biográficos, que fueron analizados mediante los presupuestos de la Metodología Comunicativo-crítica y de la Pedagogía Progresiva de Paulo Freire. Los resultados de la pesquisa apuntan contribuciones a la formación continua de educadores dentro y fuera de los espacios escolares.

Palabras-clave: Formación continua de maestros. Políticas de Formación Continua. Paulo Freire.

\section{Introdução}

Neste texto, apresentamos algumas discussões sobre a formação contínua de professores, que atuam nos anos iniciais do Ensino Fundamental, a partir de um olhar crítico sobre as políticas de formação implementadas pelo governo do estado de São Paulo, desde a década de 1980, possibilitado pelo estudo da pedagogia progressista de Paulo Freire. Estas discussões fazem parte de uma pesquisa de doutorado, financiada pela CAPES, cujo objetivo principal consistiu em verificar o potencial teórico-metodológico da práxis freireana para a construção de conhecimentos orientados à transformação das pesquisas e propostas sobre a formação dos professores e de seus formadores. Além das discussões, alguns resultados da pesquisa são demonstrados, a partir do referencial teórico-metodológico adotado.

A fim de atingir o objetivo proposto, a metodologia utilizada na pesquisa consistiu na coleta das histórias de vida de dois formadores, sendo que um deles trabalhava na elaboração das políticas de formação contínua e o outro na imple- 
mentação dessas políticas. A análise das histórias de vida foi realizada por meio dos pressupostos da Metodologia Comunicativo-Crítica (GÓMEZ et al., 2006) e do referencial teórico da Pedagogia Progressista de Paulo Freire. O percurso metodológico foi dividido em dois momentos:

$1^{\circ}$. Momento: encontros individuais com os sujeitos participantes, objetivando compartilhar suas histórias de vida por meio de entrevistas orientadas por um roteiro de enunciados que evocavam experiências, emoções, momentos, concepções, as quais emergiam de suas trajetórias pessoais e profissionais, resgatadas pela memória e relacionadas a informações necessárias para a investigação.

$2^{\circ}$. Momento: encontros entre cada entrevistado e uma das pesquisadoras, para a realização de diálogos ${ }^{1}$ sobre as análises que ela construía a respeito de cada história de vida, e sobre as aproximações e diferenciações entre as diferentes histórias. Esses encontros, realizados em duplas, a exemplo dos diálogos desenvolvidos entre Paulo Freire e outros estudiosos, em suas diversas obras, tinham por finalidade discutir e validar as análises, bem como compartilhar visões e conhecimentos, sobre os assuntos pertinentes à pesquisa, que envolviam a experiência de vida e de profissão de cada participante, visando a articulação de argumentos e posicionamentos que atendiam aos objetivos da pesquisa.

Pela impossibilidade de apresentarmos, neste texto, todas as contribuições da pesquisa para a formação dos professores e de seus formadores, optamos pela discussão crítica das políticas de formação contínua na perspectiva da Pedagogia Progressista de Paulo Freire. Os diálogos estabelecidos com os participantes da pesquisa, mediados pelo referencial teórico adotado, permitiram a construção compartilhada de considerações sobre diferentes aspectos da formação contínua, as quais trataremos no final deste texto.

O interesse pela obra de Paulo Freire, como referencial imprescindível para a realização de transformações nas pesquisas e propostas de formação contínua de professores e formadores, se deu pela constatação de que sua pedagogia progressista indica caminhos revolucionários para o fortalecimento dos educadores, na condução de suas lutas por melhores condições de trabalho e de carreira, melhores salários, melhor qualidade da educação e das escolas, melhor formação.

Ao propor uma práxis conscientizadora, fundada na ação dialógica, a partir da qual aprendemos em comunhão para a libertação de todos, Paulo Freire denuncia práticas autoritárias de manipulação, alienação e invasão cultural, que disseminam certezas históricas, a impossibilidade de mudar as relações de dominação, e anuncia uma existência pautada na incerteza, na possibilidade da mudança, nas relações de

\footnotetext{
${ }^{1}$ Os fundamentos do diálogo, que orientam o segundo momento da pesquisa, encontram-se na obra de Paulo Freire, especialmente na Pedagogia do Oprimido (FREIRE, 2004).
} 
igualdade e solidariedade, na construção conjunta do conhecimento, por meio da curiosidade epistemológica, da pergunta, da problematização do mundo.

Ao teorizar como homens e mulheres se educam, mergulhados em tempos e espaços, condicionados por situações opressoras, da mesma forma como se percebem inconclusos, capazes de reorientar suas escolhas e ações, libertando-se da condição de dominados, Paulo Freire se refere a toda a humanidade, e não apenas aos alfabetizandos adultos. Ao explicar a ação humana de conhecer, no mundo, com o mundo e com os outros, este educador desenvolve concepções sobre o papel e as ações daqueles e daquelas que assumem o compromisso com a educação de diferentes gerações, analisando e desvelando processos bancários de formação, ao mesmo tempo em que propõe o estudo da realidade, mediado pelo conceito, por meio da intersubjetividade.

A partir desta constatação, dialogar sobre as teorias de Freire e a formação dos educadores significa colocá-las em articulação, no âmbito das pesquisas e ações políticas de formação contínua que pouco se apropriam do legado desse autor para a proposição de mudanças radicais. Trazer a pedagogia progressista freireana, comumente relacionada à alfabetização de adultos e aos movimentos populares, para as discussões sobre a formação contínua de professores, nos sistemas públicos de ensino, oferece preciosas contribuições teórico-práticas para a indicação de novas abordagens do processo de desenvolvimento profissional dos professores e seus formadores.

Temos observado que a ação dos formadores que desenvolvem programas de formação contínua, elaborados e implementados pelo sistema público de educação do estado de São Paulo, atinge grande contingente de educadores, pois as certificações dos cursos oferecem vantagens na carreira e no desempenho da função docente. Além disso, a necessidade em aperfeiçoar conhecimentos, diante dos desafios enfrentados no decorrer da trajetória docente, motiva um número considerável de professores, em diferentes estágios do desenvolvimento profissional, a inscreverem-se nos cursos mencionados. Os problemas que emergem da prática pedagógica, e da estrutura dos sistemas de ensino, impulsionam os educadores à busca de alternativas para a resolução destes problemas, por meio dos programas de formação.

Apesar dos desafios frequentes, enfrentados no interior do complexo escolar, e do sentimento de desânimo e impotência sentido pelos educadores, devido às limitações impostas pelo funcionamento e pela organização do sistema político vigente, sempre constatamos, em um grande número de professores, um visível interesse em melhorar seu desempenho quanto ao ensino, o que os conduzia à busca por diferentes formas de aprendizado profissional. No entanto, apresentavam dificuldades para identificar suas reais necessidades e, comumente, deduziam 
padecer de um déficit metodológico. Por isso, procuravam descobrir e explorar novas soluções para situações pontuais, sem vislumbrarem os determinantes mais amplos dos problemas enfrentados em seu cotidiano de trabalho. Quando as alternativas encontradas não atendiam às suas expectativas, acabavam por adotar duas posições: ou estavam se mostrando ineficientes na tarefa de ensinar, ou as crianças eram incapazes de aprender. Essa situação gerava o que Esteve (1995, p. 98) denomina de "mal-estar docente", expressão que utiliza para “[...] descrever os efeitos permanentes, de caráter negativo, que afetam a personalidade do professor como resultado das condições psicológicas e sociais em que exerce a docência, devido à mudança social acelerada”.

O trabalho no interior da escola pública nos permitiu observar que os educadores não percebem que as contradições e ambiguidades presentes na organização e funcionamento do complexo escolar, e do sistema educacional, impedem uma visão mais acurada, abrangente e desveladora da realidade na qual se inserem. Este cenário salienta a relevância do papel dos formadores, quanto às relações que estabelecem com os professores por meio dos conhecimentos e procedimentos trabalhados nos programas de formação.

Muitas têm sido as queixas que os professores manifestam sobre os cursos de formação contínua, afirmando que raramente se mostram significativos e interessantes. Entre as maiores insatisfações, destacam a falta de espaço para discutirem seus saberes e suas experiências, de compartilharem seus percursos. Portanto, pensar a formação de professores implica pensar a postura de formadores, que considerem os primeiros como sujeitos de sua formação, assim como exige uma mudança de concepção sobre o que é formar professores e como formá-los.

\section{A educação contínua dos professores}

Pautando-se nos estudos de Chantraine-Demailly, Marin (1995) explica que o termo formação continuada surgiu juntamente com a concepção de formação permanente, significando modos de socialização que abrangem categorias formais e informais de ação, cuja função consciente é a transmissão de conhecimentos e procedimentos de ensino. Sob essa concepção, apresentam-se quatro modelos ideais de formação: a universitária, a escolar, a contratual e a interativa-reflexiva. Apesar das diferenças, a formação contínua guarda o significado de atividade conscientemente proposta e direcionada à mudança. Ao concluir suas análises, Marin (1995) esclarece que a denominação educação continuada envolve uma abordagem mais ampla, rica e potencial, permitindo uma visão menos fragmentada e mais inclusiva da atividade profissional, sem dicotomia entre vida e trabalho.

A respeito dos saberes que alicerçam o trabalho e a formação dos professores, mobilizados e utilizados tanto na sala de aula quanto nas escolas, Tardif 
(2004) afirma a articulação entre aspectos sociais e individuais que permitem sua construção. $\mathrm{O}$ autor explica que o caráter social se verifica na partilha dos saberes por um grupo de agentes que possuem uma formação comum, guardando certas variações, trabalham em uma mesma organização e estão sujeitos a condicionamentos e recursos comparáveis, tais como programas, disciplinas, regras da instituição, e outros. Portanto, as representações e práticas de um professor adquirem sentido apenas quando se colocam em destaque em relação à situação coletiva de trabalho. Além disso, o caráter social dos saberes se justifica pela sua posse e utilização no interior de um sistema, que garante a legitimidade deles e orienta sua definição e uso.

Em suma, um professor nunca define sozinho e em si mesmo o seu próprio saber profissional. Ao contrário, esse saber é produzido socialmente, resulta de uma negociação entre diversos grupos. [...] Por isso, no âmbito da organização do trabalho escolar, o que um professor sabe depende também daquilo que ele não sabe, daquilo que se supõe que ele não saiba, daquilo que os outros sabem em seu lugar e em seu nome, dos saberes que os outros the opõem ou lhe atribuem... Isso significa que nos ofícios e profissões não existe conhecimento sem reconhecimento social. (TARDIF, 2004, p. 13).

Apesar do número de pesquisas voltadas à construção de conhecimentos pelos professores, eles não têm sido considerados pelos programas de formação contínua como seres essencialmente sociais, imersos em relações grupais, nas quais desenvolvem valores, concepções e atitudes que dão sentido às suas opções pessoais e profissionais, e guiam suas ações. Suas formas de pensar o ensino e os alunos, suas relações com o conhecimento, assim como o valor social de seu trabalho e de sua prática, sofrem influências políticas, sociais e culturais diversas. Por isso, os processos de formação contínua não podem ignorar o que os professores pensam e sabem, bem como a influência do ambiente sociocultural em que vivem e trabalham, ao buscarem a modificação de suas atitudes, práticas e conceitos. (GATTI; BARRETO, 2009).

No entanto, considerar o que sabem, fazem e pensam não significa apenas realizar levantamentos informativos ou mapeamentos preliminares de seus conhecimentos e necessidades para ou durante os cursos de formação. Os professores desejam ser ouvidos no processo, expressando suas dúvidas e expectativas profissionais em um ambiente onde seja possível estabelecer laços sociocognitivos, afetivos e motivacionais com seus formadores e colegas de profissão, a fim de aprenderem novas ideias, concepções e alternativas de trabalho. Os professores desejam que os formadores manifestem respeito e interesse em relação ao trabalho que realizam, comprometendo-se com um propósito comum - a melhoria da formação e aprendizagem dos alunos. (GATTI; BARRETO, 2009). 
Zeichner (2003) denuncia que os planejadores educacionais e os órgãos do governo dificilmente encaram os professores como agentes importantes do processo de reforma educacional. Ao contrário disso, realizam o treinamento deles, esperando que atuem como implementadores eficientes das políticas desenvolvidas por outras pessoas, que desconhecem a sala de aula. Os projetos de reforma frequentemente intencionam manter os professores como funcionários irreflexivos e obedientes, que saibam implementar eficientemente o currículo prescrito pelo Estado, e empregar os métodos de ensino igualmente prescritos. A maioria dos investimentos em educação tende à aquisição de livros-texto e tecnologias, não às pessoas, pois não há interesse no desenvolvimento da capacidade dos professores em analisarem as questões educacionais, dentro e fora da sala de aula, adquirindo auto monitoramento para aprender com a própria prática, no decorrer da carreira.

Em consequência, a divulgação e a exigência de mudanças não conseguem garantir alterações nas situações de sala de aula e nas escolas, pois os professores resistem a elas ou as subvertem. Considerando as formas autoritárias de transmissão do conhecimento que predominam nas escolas, os professores apenas adotarão um ensino democrático e centrado nos alunos se vivenciarem uma reorientação conceitual sobre seus papéis e a natureza do ensinar e o aprender. Nesse sentido, mudanças qualitativas na prática da sala de aula poderão ocorrer se os professores as compreenderem e assumirem como suas. Planos de reforma que os obrigam a trabalhar de determinada maneira, sem lhes conferir um papel importante na composição e na interpretação das reformas, são subvertidos pelos professores. (ZEICHNER, 2003).

Não estou questionando o direito ou a conveniência de um governo estabelecer uma orientação clara para o ensino em um país. Isso é importante por muitos motivos. O que me parece questionável é o modo como os professores têm sido encarados e tratados na implementação desses planos. Na minha opinião, ao estabelecer diretivas para a reforma educacional, os governos precisam adotar mecanismos para que os educadores tenham um papel central na criação, na interpretação e na implementação dessas reformas, o que se aplica também aos professores dos chamados "países em desenvolvimento". (ZEICHNER, 2003, p. 39).

Ghedin (2004) também denuncia a postura autoritária e antidemocrática que orienta as reformas no ensino e na formação de professores, movidas por instâncias superiores, que impõem um conjunto de mudanças às escolas e aos professores, cuja discussão pública e política não foi proposta. O autor explica que as reformas trazidas pela Lei de Diretrizes e Bases da Educação Nacional, Lei 9394/1996, negaram o debate democrático que estava acontecendo em um contexto de mudanças, colocando os professores longe das propostas de reforma. Estes profissionais têm sido encarados, no imaginário político, como meros 
operadores sociais, destituídos de compreensão da totalidade e da complexidade das relações que se dão na sociedade, o que tem gerado uma determinada forma de exclusão dos professores em relação às instâncias de decisão. A autonomia dos professores não interessa ao poder político, pois a crítica de centenas deles causaria um impacto indesejado na estrutura da sociedade. Por isso, é melhor que permaneçam como técnicos, que operam ferramentas colocadas à disposição pelas políticas da reforma.

Para Almeida (2006), estudiosos e analistas dos processos de reformas educativas concordam que os professores desempenham um papel fundamental na efetivação das mesmas. As mudanças no campo da educação provocam impactos diretos no modo de pensar e agir dos educadores, ou seja, implicam nova atitude quanto ao planejamento, ao ensino, à organização do conhecimento, à avaliação e outras tarefas, o que significa atentar para a dimensão pessoal envolvida nesse processo. Por essa razão, é preciso que as reformas os envolvam desde a fase de desenvolvimento profissional, assegurando programas de formação contínua que possam ajudá-los a responder aos novos desafios.

A relação do professor com sua formação é muito mais complexa do que a que comumente vemos ser implementada em muitas das políticas educacionais em vigor, regra da qual nosso país não escapa, centradas ainda na organização de programas de aperfeiçoamento ou capacitação. Compreender o professor como sujeito de suas práticas, analista do contexto em que atua, articulador dos conhecimentos teóricos com as dinâmicas sociais e necessidades de aprendizagem de seus alunos e construtor de conhecimentos acerca da profissão, têm relação direta com as novas dimensões de atuação que lhe têm sido colocadas e vão além dos contornos estabelecidos pela concepção técnica do fazer docente. (ALMEIDA, 2006, p. 180).

Os professores têm sido chamados a responder demandas de diferentes naturezas: na perspectiva social, tem necessidade de aprender a conviver intensamente com os interesses e formas de pensar de alunos e famílias no cotidiano da escola, interagindo com a comunidade de entorno; na perspectiva institucional, é solicitado a participar ativamente nas decisões sobre questões pedagógicas e políticas da escola, a selecionar os conhecimentos a serem trabalhados, a elaborar e conduzir projetos; na perspectiva pessoal, deve tomar decisões constantes sobre seu percurso formador e profissional, deve romper com a cultura do isolamento pelo envolvimento em discussões coletivas e projetos, debatendo e reivindicando condições para viabilizar o próprio trabalho. (ALMEIDA, 2006).

Considerando esse contexto, Almeida (2006) argumenta sobre a importância de uma concepção ecológica da formação docente, que contemple a comunidade, o indivíduo, o coletivo, a instituição, as decisões e atitudes dos educadores em seus contextos, transformando sua atuação e os saberes que a sustentam. Essa 
formação deverá tomar a prática educativa e o ensinar como objetos de análise, assegurando que os professores possam compreender as relações entre a sociedade e os conhecimentos produzidos e desenvolver a atitude de pesquisa como forma de aprendizado.

Em relação às tendências de abordagem da profissionalização docente e da formação contínua de educadores, Zeichner (2003) observou que houve, nos últimos vinte anos, uma explosão na literatura quanto à preparação dos educadores como agentes reflexivos, que desempenham importante papel nas decisões sobre o que ocorre na sala de aula e na escola, e devem assumir a responsabilidade pelo próprio desenvolvimento profissional. Pode-se constatar, neste período, a adoção dos slogans "ensino reflexivo", "pesquisa-ação", "valorização do professor", entre professores, educadores de professores e pesquisadores educacionais de todo o mundo. O movimento que se desenvolveu na educação de professores, sob essa perspectiva, constituiu uma reação à visão dos educadores como técnicos, que apenas executam o que outros determinam, e contra as formas verticalizadas de reforma educacional, que encaram os professores como participantes passivos.

O movimento pela prática reflexiva parte do reconhecimento de que os educadores devem participar ativamente das reformas educacionais, considerando que a produção de conhecimentos sobre o ensino e a aprendizagem não são propriedade exclusiva das universidades e centros de pesquisa e os educadores também desenvolvem teorias capazes de contribuir para a construção de conhecimentos acerca das boas práticas. Como palavra de ordem da reforma educacional, a reflexão significa também reconhecer que o processo de aprendizagem do ensino se estende por toda a carreira e que os programas de formação de educadores, mesmo diante de constante aperfeiçoamento, só poderão oferecer preparo para o início do trabalho docente. (ZEICHNER, 2003).

Zeichner (2003) explica que, apesar da semelhança entre aqueles que adotam o slogan do ensino reflexivo, há muitas diferenças nas perspectivas sobre o ensino, a aprendizagem, a educação e a ordem social. Muitos acadêmicos têm analisado diversas formas de ensino reflexivo que surgiram, outros têm se dedicado a estudar as diferentes pedagogias que os formadores têm empregado para promover modelos particulares de ensino reflexivo, como a pesquisa da ação, os portfólios e os diários de ensino. Na análise de Zeichner (2003), a formação reflexiva de professores pouco contribuiu para fomentar o verdadeiro desenvolvimento dos educadores e valorizar seu papel na reforma, criando apenas a ilusão desse desenvolvimento e conservando, de forma sutil, a posição subserviente dos professores.

Segundo Zeichner (2003), a formação reflexiva solapou a tentativa emancipadora dos formadores de educadores, pois o conceito de reflexão tem sido comumente empregado para ajudar os professores a refletirem sobre suas 
atividades, a fim de melhor reproduzirem na prática o que a universidade julga eficaz. Em alguns momentos, permite-se que os professores intervenham com sua criatividade no intuito de decidir sobre a adequação situacional do emprego de procedimentos particulares, o que geralmente não ocorre. Falta a essa concepção de ensino reflexivo, saber como as teorias implícitas nas práticas dos educadores poderão contribuir para o processo de desenvolvimento deles.

Um outro aspecto do fracasso da formação reflexiva de professores em promover o desenvolvimento genuíno do educador é a clara ênfase em enfocar internamente as reflexões dos professores, sobre sua própria atividade ou seus alunos, negligenciando toda e qualquer consideração acerca das condições sociais do ensino que influenciam seu trabalho na sala de aula. Essa tendência individualista torna menos provável que os professores consigam enfrentar e transformar tais aspectos estruturais de sua atividade, que os impedem de atingir suas metas educacionais. O contexto do trabalho do educador deve ser tomado tal como é dado. Ora, embora seja compreensível que as preocupações dos professores são principalmente a sala de aula e os alunos, é insensato restringir-lhes a atenção exclusivamente a essas preocupações. (ZEICHNER, 2003, p. 44).

Investigando as concepções de formação docente que têm orientado a configuração das políticas públicas no Estado de São Paulo, para o desenvolvimento de educadores nas últimas três décadas, Borges (2004) revela que a maior parte das ações de formação tem ocorrido por meio de três vias: multiplicadores, capacitadores ou professores. A resposta do estado às demandas quanto à educação contínua de professores vem sendo oferecida de três maneiras: por meio dos órgãos da Secretaria, como a CENP (Coordenadoria de Estudos e Normas Pedagógicas), e FDE (Fundação para o Desenvolvimento da Educação), que participaram de formas diferentes em momentos distintos; pelo ensino a distância e mediante parcerias e terceirizações.

De acordo com Borges (2004), a organização burocrática da Secretaria da Educação se estrutura a partir da reforma administrativa e pedagógica de 1976, devido às demandas colocadas a partir da Lei 5692/1971, que exigia a ampliação de seus órgãos para atender as necessidades daquele período. Nos anos de 1970 verificou-se um grande contingente populacional, formado pela chegada de migrantes e pelo crescimento da região metropolitana de São Paulo, que necessitava de atendimento educacional. Nesse contexto, medidas foram tomadas no plano técnico-pedagógico para oferecer novos métodos e técnicas aos educadores, visando o aperfeiçoamento da educação e do ensino. Essas medidas, em sua maioria pontuais, sem maiores reflexões sobre a totalidade do sistema, caracterizaram-se pela fragmentação, desarticulação e descontinuidade nas formas 
de implementação dos programas, sem contemplar a participação dos agentes escolares, seus maiores interessados.

Em relação à política educacional do estado, Borges (2004) identificou duas lógicas: a inovadora, modernizante e descentralizadora, presente no discurso e no desenho dos programas; a conservadora, evidenciada no burocratismo e na centralização. Essas lógicas quase não se modificaram ao longo dos anos. Além disso, o autor constatou que há sérias contradições entre o que determinam os órgãos centrais e as necessidades reais da rede de ensino.

Para Borges (2004), as expectativas, vivências e histórias de vida dos professores que chegam aos cursos são diferenciadas e deverão ser compreendidas, reconhecidas e trabalhadas no processo de formação de sua identidade profissional. Por isso, os cursos precisam ser repensados, considerando que incidem fortemente sobre aspectos técnicos e desprezam as dimensões pessoais e culturais. Além desses problemas, os programas de formação contínua desenvolvidos pela Secretaria de Estado da Educação de São Paulo não consideram fatores importantes para sua elaboração e implementação: os baixos investimentos financeiros na educação, as condições de trabalho dos professores, de organização e funcionamento das escolas, bem como os conflitos que ocorrem no cotidiano destas.

Os programas se alicerçam em certas concepções de educação, que constituem instrumentos para a sustentação das políticas hegemônicas do estado, e não atendem aos problemas educacionais, pela falta de visão crítica do processo educativo, enquanto fenômeno histórico e social. Verifica-se, nesses programas, uma grande ênfase dada aos aspectos metodológicos, por meio de ações que deslocam os professores das escolas, cujo contexto de contradições deveria tornar-se objeto de reflexão. Nesse sentido, a formação contínua deve prever a articulação com o projeto político pedagógico da escola, envolvendo trabalhos de investigação-ação-reflexão, que contribuam para elevar a qualidade do ensino; deve abranger a análise de sua cultura organizacional, captando a forma como interage com o meio social e político, bem como com a comunidade. (BORGES, 2004).

Evidencia-se, na estruturação da rede pública estadual paulista de ensino, uma concepção neotecnicista de educação, orientada por ideais de mercantilização da educação, cujo objetivo é a sua privatização, o que acarreta problemas à formulação e implementação de uma política de formação contínua. Mantendo tal tendência, dificilmente os dirigentes da Secretaria de Estado da Educação poderão proporcionar programas de formação contínua que produzam bons resultados, de natureza quantitativa e qualitativa, atendendo às necessidades da rede de ensino. (BORGES, 2004).

Na mesma direção dos argumentos de Borges (2004), Candau (2001) focaliza três teses referentes aos caminhos para a construção de uma nova perspectiva de 
formação contínua, os quais sintetizam eixos de investigação que vem ganhando consenso entre os profissionais da educação: privilegiar a escola como lócus de formação; assumir o saber docente como referência fundamental para os processos de formação, reconhecendo-o e valorizando-o; considerar as diferentes etapas de desenvolvimento profissional do Magistério, tratando de forma específica os educadores que se encontram na fase inicial da carreira e aqueles que já conquistaram ampla experiência pedagógica, pois seus problemas, necessidades e desafios são diferentes, evitando situações homogêneas e padronizadas.

Candau (2001) ressalta a desvalorização dos conhecimentos construídos pelos professores, por parte das propostas de formação, afirmando que, geralmente, a universidade resiste em reconhecer, valorizar esse conhecimento e apostar em sua interação com o conhecimento acadêmico. Nos cursos que oferecem aos educadores da rede, a universidade age de modo a partir do ponto zero, sem estabelecer um confronto entre os saberes da experiência e os academicamente produzidos, ignorando os ciclos profissionais vivenciados pelos professores, os quais sofrem influência de múltiplas variáveis.

A formação continuada não pode ser concebida como um meio de acumulação (de cursos, palestras, seminários, etc., de conhecimentos ou de técnicas), mas sim através de um trabalho de reflexividade crítica sobre as práticas e de (re)construção permanente de uma identidade pessoal e profissional, em interação mútua. E é nessa perspectiva que a renovação da formação continuada vem procurando caminhos novos de desenvolvimento. (CANDAU, 2001, p. $65)$.

Concordando com tais críticas, Marin (2003) esclarece que não somente na formação dos educadores, mas também dos demais profissionais, o paradigma linear que fundamenta as propostas está presente. As pessoas que conduzem as modalidades de formação concebem os estudantes de seus cursos como desprovidos de saberes sociais e profissionais, manifestando nos cursos posturas que criticam nos professores que analisam. A autora enfatiza que qualquer processo de formação profissional carrega uma história, que é constituída no cotidiano em que se vive, por meio da educação formal e informal, desde a mais tenra idade. "É na interação social, na família, nos grupos de amigos, nas instituições, nas horas de lazer que começa essa formação, não nos cursos básicos que ministramos”. (MARIN, 2003, p. 162).

As imagens, crenças, valores, gostos ou desgostos, preferências ou preconceitos quanto à profissão, que os professores trazem para os cursos, não tem representado um dado de reflexão considerado pelas propostas de formação. Por isso, Marin (2003) sugere a adoção de um paradigma com fundamento histórico e social que embase os cursos, englobando as histórias de vida, o processo 
de socialização, as expectativas, as crenças, os valores, as representações que os professores apresentam no início dos cursos, como subsídio para o trabalho. Uma vez consideradas, essas informações poderão ser trabalhadas no decorrer do curso, por meio de atuações que correspondam ao quadro de referência dos professores. (MARIN, 2003).

Marin (2003) defende, portanto, a incorporação de uma concepção de formação mais ecológica, que permita a articulação das vivências dos professores a um projeto político pedagógico de curso, e conduza à concretização dos sonhos que detemos.

Pautadas neste paradigma, encontramos também as pesquisas de Mizukami et al. (2002), que propõem intervenções/ações de natureza construtivo-colaborativa no local de trabalho, destinadas ao conhecimento e à promoção de processos de desenvolvimento profissional de professores. Esse trabalho se contrapõe à ideia de formação como sinônimo de eventos, geralmente de curta duração, que se apoia no acúmulo de conhecimentos teóricos para posterior aplicação no âmbito da prática, coerente com a lógica da racionalidade técnica.

O conhecimento profissional é concebido como um conjunto de fatos, princípios, regras e procedimentos que se aplicam diretamente a problemas instrumentais.

Essa concepção é compatível com a visão do saber escolar como um conhecimento que os professores possuem e que deve ser transmitido aos alunos. O saber escolar, privilegiado em detrimento do conhecimento do aluno, é entendido como verdadeiro, molecular - no qual peças isoladas podem ser agrupadas de maneira a compor um conhecimento mais avançado - e categorial. (MIZUKAMI et al., 2002, p. 13).

De acordo com Mizukami et al. (2002), a concepção de formação como um continuum representa a superação do paradigma da racionalidade técnica, amparando-se no da racionalidade prática. Nesta perspectiva, a formação integra-se em um modelo reflexivo e artístico, baseando-se na concepção construtivista da realidade na qual os professores se inserem, pela compreensão de que constroem conhecimentos profissionais de maneira idiossincrática e processual, incorporando e transcendendo o conhecimento resultante da racionalidade técnica. A visão de formação como um continuum implica o necessário estabelecimento de um fio condutor, produtor de sentidos e significados ao longo da vida, que gera nexos entre a formação inicial, a formação contínua e as experiências vividas.

Ao preconizar uma formação que se desenvolva no cotidiano da escola, Fusari (2000) argumenta que os professores da Educação Básica deveriam ser contratados e remunerados para uma jornada de trabalho que abrangesse a atuação na docência (aulas), em atividades pedagógico-administrativas (reuniões, conselho de 
classes, horas-atividade pedagógicas) e em ações de formação contínua em serviço, junto ao coletivo da própria escola, a exemplo do que ocorre nas universidades públicas, e em algumas particulares, nas quais se contratam professores para o desenvolvimento concomitante de atividades de ensino, pesquisa e extensão.

Fusari (2000) acredita no sucesso de uma iniciativa de formação que possa congregar todos os seus profissionais em um projeto coletivo de educação contínua, prevendo momentos do ano em que toda a escola se reúna para repensar-se e repensar o trabalho que desenvolve. Essa iniciativa uniria a gestão escolar, os agentes administrativos, o corpo técnico, os professores, especialistas, representantes de alunos e da comunidade.

O ideal, segundo Fusari (2000), seria a proposição de uma formação contínua que ocorresse num processo articulado fora e dentro da escola. Participar de oportunidades de formação fora da escola pode significar o distanciamento do próprio trabalho, olhando-o sob novas perspectivas, para avaliá-lo e avaliar a atuação dos colegas. "Outro exemplo interessante é a participação dos educadores em encontros e congressos regionais, estaduais e nacionais, nos quais conhecem pessoas diferentes, autores, obras, trocam experiências, ampliam contatos, trocam materiais, etc". (FUSARI, 2000, p. 19).

Para Fusari (2000), assim como para os demais autores citados, os projetos de formação contínua poderão ser bem sucedidos se valorizarem, respeitarem e ouvirem os professores, identificando as teorias que praticam e criando situações para que possam analisar e criticar suas práticas, refletir e dialogar sobre elas, com base em novos fundamentos teóricos, trocas de experiências e propostas de superação das dificuldades que enfrentam. Para isso, a gestão democrática é de essencial importância na valorização da participação e do envolvimento de professores e técnicos, podendo atuar na organização de um calendário escolar que garanta oportunidades de encontro entre professores, para a análise, problematização, reflexão de conhecimentos e experiências. Nesta configuração, a formação contínua não será caracterizada como algo eventual, esporádico, mas como atividade inerente ao trabalho educativo realizado pela escola.

O autor salienta ainda, que a formação contínua, fora e dentro da escola, depende também das atitudes dos professores diante de seu desenvolvimento profissional.

Não podemos relegar a formação contínua exclusivamente à responsabilidade do Estado. Cada educador é responsável por seu processo de desenvolvimento pessoal e profissional; cabe a ele o direcionamento, o discernimento e a decisão de que caminhos percorrer. Não há política ou programa de formação contínua que consiga aperfeiçoar um professor que não queira crescer, que não perceba o valor do processo individual-coletivo de aperfeiçoamento pessoal-profissional. (FUSARI, 2000, p. 22). 
$\mathrm{Na}$ atualidade, conforme constatamos junto aos autores abordados neste texto, presenciamos um movimento de reconceitualização da formação contínua, instaurado pela produção acadêmica empenhada na investigação de questões referentes à identidade profissional do professor. Um novo paradigma, centrado no potencial de auto crescimento dos professores e no reconhecimento de suas bases de conhecimentos, sobre as quais poderão ser trabalhados novos conceitos e opções, ocupa o lugar das propostas pautadas no conceito de capacitação. Nesta perspectiva, grande importância é atribuída às representações, atitudes, motivações dos professores para a implementação de mudanças e a produção de inovações na prática educativa. O protagonismo dos professores é valorizado e torna-se central nos projetos de formação contínua, superando a lógica dos processos educativos que desconsideram suas trajetórias profissionais. (GATTI; BARRETO, 2009).

De acordo com este novo paradigma, a formação se dá como um contínuo, ao longo da vida, e é definida como desenvolvimento profissional, como um movimento orientado para o enfrentamento de desafios que se colocam nas diferentes fases da vida profissional. Para exemplificar esse paradigma, Gatti e Barreto (2009) mencionam uma experiência de perfil político claramente envolvido com a qualidade da educação, efetivada pela Secretaria Municipal da Educação de São Paulo, entre 1989 e 1992, e proposta pelo educador Paulo Freire - o Projeto Grupos de Formação - que atingiu todas as escolas, adotando uma dinâmica de formação que favorecia o protagonismo dos educadores. O projeto criou um estatuto do magistério que previa 40 horas de trabalho semanal remunerado, sendo 20 na docência e 20 dedicados aos estudos, planejamentos, formação. (GATTI; BARRETO, 2009).

Paulo Freire, sempre preocupado com a concretização de uma educação emancipadora, crítica, libertadora, no âmbito das políticas, das concepções e das práticas educativas, nos oferece caminhos epistemológicos e objetivos para superar a educação bancária de estudantes, professores e formadores. É sobre isso que passaremos a tratar.

\section{A Pedagogia Progressista de Paulo Freire e a formação dos professores e seus formadores}

Partindo de uma concepção histórica, crítica, política e humanista de educação, Freire (1996) enfatiza que o conteúdo sozinho não liberta ninguém e que nunca necessitamos tanto da unidade dialética contraditória entre a leitura da palavra e a leitura do mundo, a relação entre texto e contexto, que não serve aos liberais, empenhados em oferecer uma educação pragmática, que permaneça estagnada na palavra. Isso significa que a classe dominante admite a instrução, mas não aceita a leitura crítica da história. Portanto, é preciso que, enquanto educadores 
e políticos, tenhamos clareza em relação às nossas opções, pois nosso sonho não é pedagógico, mas sempre político.

E, se optamos por sermos educadores progressistas, não podemos concordar com a transmissão de parcos conhecimentos técnicos aos profissionais, o que se mostraria cientificamente absurdo. Considerando o processo de conhecer, do qual somos sujeitos e objetos, observamos que homens e mulheres, no decorrer da história, vêm transformando a vida em existência, o que não ocorre sem a linguagem, a produção de conhecimento, a transformação. No entanto, o conhecimento não pode ser transferido, mas discutido, a partir da curiosidade que impulsiona as pessoas ao questionamento sobre o mundo, e a insatisfação com as certezas. (FREIRE, 1996).

Creio que uma das características da chamada modernidade, com a chegada da ciência e da regulamentação da chamada objetividade, é a exagerada certeza na certeza. Uma das características da pós-modernidade é exatamente já não estarmos muito certos das certezas e continuarmos a nos perguntar e a nos testar. Enquanto educadores progressistas, é essa a educação que me parece nos deveríamos obrigar a desenvolver, a praticar com os nossos companheiros, povo brasileiro. Não uma educação da pura memorização mecânica, e não o escamoteamento de verdades. (FREIRE, 1996, p. 42).

Para Freire (1996), a educação de seres históricos, fazedores e refazedores de mundo, é a educação que desoculta, que se firma ao lado das massas. Uma educação que envolve pessoas em todas as situações: como educadores, educandos e formadores de educadores.

Sob a perspectiva das concepções de Freire (2004), a tarefa dos formadores de professores é crer na capacidade dos educadores de pensar certo, do contrário, a ideia do diálogo, da reflexão, da comunicação será abandonada em favor do dirigismo, da manipulação. E pensar certo é reconhecer que as certezas são provisórias, são históricas; é admitir que o saber que se detém pode ser melhorado, que o saber que não se detém pode ser assimilado e que todos podem produzir conhecimento existente. (FREIRE, 2004). Nesta perspectiva, professores e formadores são sujeitos do processo de formação, da recriação do conhecimento envolvido nesse processo.

Falar da realidade como algo parado, estático, compartimentado e bem-comportado, quando não falar ou dissertar sobre algo completamente alheio à experiência existencial dos educandos vem sendo, realmente, a suprema inquietação desta educação. (FREIRE, 2004, p. 44).

A formação dos educadores tem se orientado por uma concepção bancária da educação, na qual as informações são depositadas, à espera de que se transformem em práticas. De acordo com esta concepção, o saber é uma doação 
dos que se julgam sábios aos que julgam nada saber, doação que se manifesta na alienação da ignorância, segundo a qual esta se encontra sempre no outro. Desta forma, se concebidos pelos formadores como seres do ajustamento, da adaptação, os professores não desenvolverão em si a consciência crítica e não se tornarão transformadores. (FREIRE, 2004).

Freire (2004) adverte que pensar autenticamente é perigoso. No entanto, um formador humanista perceberá que o seu pensar somente ganhará autenticidade na autenticidade do pensar dos professores, quando mediatizado pela realidade escolar. Se causar obstáculos à atuação dos educadores, como sujeitos de sua ação, irá frustrá-los e fazê-los sofrer na impossibilidade de usarem suas capacidades.

O diálogo, imprescindível à significação das pessoas e à transformação do mundo por elas, requer humildade e tolerância, a fim de que se possa conviver com o diferente para poder lutar contra o antagônico. (FREIRE; FAUNDEZ, 2002; FREIRE, 2004).

Freire (2004) utiliza os conceitos educador-educando e educando-educador para explicitar a essência de uma educação problematizadora, segundo a qual ninguém educa ninguém e ninguém educa a si mesmo, pois as pessoas se educam em comunhão, nas relações dialéticas que estabelecem com o mundo. Por isso, a atuação de cada pessoa deve ser compreendida em função de como ela se percebe no mundo. Para Freire (2004) impedir que os outros sejam sujeitos de sua busca, instaura uma situação violenta. $\mathrm{O}$ autor argumenta que "embora diferentes entre si, quem forma se forma e re-forma ao reformar e quem é formado forma-se e forma ao ser formado." (FREIRE, 1998, p. 25).

Portanto, professores e formadores devem se constituir em sujeitos de seu processo de formação, superando o intelectualismo alienante, o autoritarismo do educador "bancário" e a falsa consciência de mundo. Assumir tal postura na formação de professores implica uma investigação acerca do próprio pensar e do pensar e atuar dos educadores no enfrentamento de situações-limites, inseridos em suas realidades, o que constitui sua práxis. Desta forma, os educadores poderão aprofundar sua tomada de consciência sobre essa realidade, apropriando-se dela. (FREIRE, 2004).

Fundamentar a formação dos professores e formadores nos princípios da pedagogia freireana torna necessário analisar a temática dos educadores em suas relações com a realidade, pois suas aspirações, motivos, finalidades são históricas e não se encontram estáticas, mas estão sendo e não podem ser captadas fora delas. Os homens e mulheres, enquanto seres inconclusos, são históricos, autobiográficos, se desenvolvem no tempo que é deles e numa determinada cultura. Em virtude disso, devem-se evitar rígidos juízos de valor diante das diferenças culturais. (FREIRE, 2002). 
Conforme afirma Freire (2004), investigar o pensar do povo com ele é um processo de educação em conjunto. Portanto, o formador não poderá temer os educadores, a sua expressividade, sua participação no poder. Não poderá negá-los. A adoção de preconceitos é contrária a uma formação dialógica, a uma atitude de humildade e respeito com relação aos educadores, assim como a transmissão de respostas às questões cotidianas se mostra uma conduta autoritária.

Numa discussão sobre a natureza desafiadora da pergunta, Freire (2002) explica que, ao limitar a curiosidade do aluno, o educador limita a sua também. Frequentemente, o educador apresenta respostas na ausência de perguntas, sugerindo que estas últimas são cômodas. Tal situação também é característica dos modelos de formação atuais, que não partem do universo experiencial dos educadores, revelando que "toda prática educativa que se funda no estandartizado, no preestabelecido, na rotina em que todas as coisas estão pré-ditas, é burocratizante e, por isso mesmo, antidemocrática." (FREIRE, 2002, p. 52).

No entender de Freire (2002), constitui um erro considerar que a aplicação de conceitos e categorias científicas abstratas irá transformar a realidade. Estes conceitos e categorias nunca serão absolutos e deverão sofrer uma leitura da realidade. Portanto, professores e formadores devem perguntar-se sobre tais conceituações, pois a ciência não é a-histórica; ela se transforma constantemente e não é capaz de mudar a realidade sozinha. Ao mediar a compreensão da realidade, o conceito poderá se esvaziar se estiver distante do concreto, e se perderá na pura descrição. A verdadeira ciência parte do concreto e, mediada pelo conceito, volta ao concreto. (FREIRE, 2002).

Freire (2005) argumenta que o saber está sempre sendo, que é histórico, assim como tudo que se vivencia, se produz, se pensa. Por ser histórico, é possibilidade e não determinismo, o que torna as pessoas condicionadas, mas não determinadas. Por sua vez, reconhecer a História como tempo de possibilidade é reconhecer o ser humano como ser da decisão e da ruptura, o que implica falar em ética. "A possibilidade de discernir, comparar, escolher, programar, atuar, avaliar, nos comprometer, nos arriscar, faz-nos seres da decisão, portanto, seres éticos." (FREIRE, 2005, p. 70).

E comprometer-se eticamente com a formação dos educadores é admitir que não há neutralidade na educação; é reconhecer que "estando a favor de algo e de alguém, me acho necessariamente contra alguém" (FREIRE, 2005, p. 27); é posicionar-se frente à prática educativa afirmando sua intenção desveladora, sem reduzi-la à pura transferência de conteúdos, que adapta o ser humano ao mundo sem protestos nem sonhos de transformação.

Para Freire (2005, p. 27), “o domínio técnico é tão importante para o profissional quanto a compreensão política o é para o cidadão. Não é possível separá- 
los.” A despolitização da educação, que sempre interessou às classes dominantes, marcou a formação dos educadores com o academicismo e o tecnicismo, negando a curiosidade epistemológica e excluindo as questões sociais e político-ideológicas do debate. O formador democrático e ético respeita a liberdade dos educadores, sem prescindir da rigorosidade metódica ao realizar a passagem do conhecimento do âmbito da consciência ingênua para o âmbito da curiosidade epistemológica, juntamente com os educadores.

$\mathrm{O}$ autor ressalta que:

Transformar a experiência educativa em puro conhecimento técnico é amesquinhar o que há de fundamentalmente humano no exercício educativo: o seu caráter formador. Se se respeita a natureza do ser humano, o ensino dos conteúdos não pode dar-se alheio à formação moral do educando. Educar é substantivamente formar. (FREIRE, 1998, p, 37).

Freire (1998) enfatiza que o aprendiz deve superar o pensar ingênuo, produzindo o pensar certo, em comunhão com o professor. Neste sentido, também o formador de professores deverá propiciar condições para que os educadores, em suas relações com outros educadores e com o formador, ensaiem a experiência de assumirem-se. "Assumir-se como ser social e histórico, como ser pensante, comunicante, transformador, criador, realizador de sonhos, capaz de ter raiva porque capaz de amar." (FREIRE, 1998, p. 46).

Essa tarefa é complexa, mas coerente com o contexto de revoluções tecnológicas que diminuem o tempo entre uma mudança e outra, mobilizando os educadores a estarem abertos aos riscos, inovações e dúvidas.

\section{Considerações sobre a contribuição da práxis freireana às políticas sobre formação contínua dos professores}

Nos dias atuais, representados pela segunda década do século XXI, ainda verificamos a necessidade e a urgência de uma educação humanista, crítica, desveladora, ética e totalizante, que integre a leitura de mundo e a leitura da palavra, a fim de que possamos nos preparar para o enfrentamento das ideologias, das lutas de classe e das formas de dominação que, embora negadas dentro das complexas relações sociais que se modificam constantemente, nos oprimem cotidianamente e exigem o repensar de táticas para a concretização de transformações, na vida comum e nos sistemas.

Ao constatar, por meio da revisão e reflexão da obra de Paulo Freire, que sua práxis histórica é tão atual e necessária à educação das crianças, jovens e adultos da atualidade quanto a tecnologia, nos propusemos a demonstrar o potencial dessa práxis para os trabalhos científicos e práticos de educação contínua dos educadores 
e seus formadores. Afinal, esses profissionais detêm a capacidade de lançar as bases para o desenvolvimento de processos humanizadores ou desumanizadores nas relações que estabelecem, como se tem verificado historicamente.

Freire (2004) afirma que a pedagogia do oprimido deve ser forjada com ele e não para ele, na luta pela recuperação de sua humanidade. E oprimidos são também os educadores que sofrem com o descaso dos poderes políticos, o autoritarismo vigente nas instituições e sistemas de ensino, as precárias condições de trabalho, a desvalorização profissional e social, os baixos salários, o sucateamento da educação pública, os dilemas, conflitos e problemas vivenciados no contexto escolar, a insuficiente e inadequada formação, entre outros fatores.

Portanto, os professores, juntamente com os formadores, necessitam superar a condição de oprimidos pela inserção crítica na realidade, na e pela busca do direito de ser, do qual são privados pelos que limitam sua capacidade de pensar o próprio trabalho, condicionando-os ao papel de meros executores de práticas (FREIRE, 2004). Para Freire (2004), toda forma de mediação entre os indivíduos, caracterizada pela prescrição, se constitui em uma imposição. Pela alienação que acarreta, a prescrição torna a consciência "hospedeira" da consciência opressora.

Por tudo isso, Paulo Freire defendeu uma aprendizagem que se dá pelo corpo e que justifica sua práxis histórica, educativa, popular, política, progressista, radical, revolucionária, humanista, amorosa; uma dialética inerente à existência humana, presente nas relações sujeito-mundo, ação-reflexão, conceito-concreto, texto-contexto, humanização-desumanização; uma visão crítica, problematizadora, totalizante, transformadora de mundo; uma forma dialógica de conhecer em comunhão: ouvindo, respeitando, posicionando-se, investigando.

Enquanto pesquisadoras da temática da formação dos educadores, que buscam coerência com as idéias de Paulo Freire, nos estudos sobre a aprendizagem da docência, ao longo da vida e da trajetória de profissionalização, optamos por nomear esse processo de constituição, pois o termo sugere uma forma ampla de explicar como nos tornamos indivíduos e profissionais, mediante modos próprios de viver as experiências. Constituir-se envolve relações entre elementos intrínsecos (dos indivíduos) e extrínsecos (do meio), que nos desafia a aprender com o corpo inteiro, quando algo nos move a refletir, agir, decidir, resistir. Nesta perspectiva, ninguém pode constituir o outro, nem tampouco consegue constitui-se sozinho, na solidão e no vazio, pois esta ação requer um movimento dialético entre os elementos que se colocam de dentro para fora, e de fora para dentro das pessoas.

Pela preocupação que mantemos em considerar uma visão totalizante na abordagem do tema, consideramos impossível separar os fatores que integram o processo de profissionalização docente, como: as tendências teóricas identifica- 
das nas pesquisas e propostas de formação, as políticas educacionais em geral e aquelas voltadas à formação dos educadores, a formação escolar e universitária inicial, a organização e o funcionamento das instituições de ensino, as condições de trabalho, carreira e salário impostas aos professores, a situação material em que se encontram as escolas, entre outros.

Não poderíamos ignorar nesta contextualização, a resistência que os educadores têm demonstrado contra a precariedade de vida e a desvalorização social às quais vêm sendo submetidos há anos pelo poder público, que despreza seus movimentos e reivindicações. Ao tomarem medidas paliativas, privilegiando a efetivação de reformas que não visam a eliminação dos problemas, ou atendem apenas a um aspecto deles, respondendo ao interesse de acordos políticos internacionais, as autoridades públicas investem menos do que deveriam, e de forma inadequada, no setor educacional. Ao deixarem de apostar nas pessoas, integrando diferentes medidas, que atendam aos estudantes, educadores e escolas, o poder político privilegia a injeção de verbas nos meios de ensino - materiais didáticos como se estes, por si só, eliminassem os problemas acarretados durante anos de descompromisso e negligência com a educação pública.

É preciso enfatizar, no entanto, que ao defendermos investimentos e transformações na esfera da educação contínua dos educadores, não a tomamos como panacéia para todos os males enfrentados no sistema educacional público, mas, acreditamos que apenas os seres humanos, enquanto sujeitos da verdadeira transformação, dotados de inteligência e capacidade de decisão, podem mobilizar fins e meios para construírem historicamente suas realidades, compreendendo e refazendo seus contextos, lutando por melhores condições de trabalho e vida.

Se somente os oprimidos e oprimidas podem libertar-se da opressão, libertando também seus opressores, como nos mostra Paulo Freire (2004), a ação conjunta dos educadores se faz urgente para as pequenas e grandes transformações, numa época em que suas manifestações políticas têm se mostrado enfraquecidas pelo desencanto, pela desesperança, pelo descrédito na mudança e no potencial do próprio trabalho.

Apostando na educação como ação cultural (FREIRE, 2004) emancipadora, que deverá olhar para os educadores em todas as suas necessidades, condições, emoções e lutas, sem esquecer que são seres humanos completos e históricos, vivendo uma complexidade de situações - sociais, culturais, econômicas, pedagógicas, relacionais, institucionais, etc - que demandam sua ação consciente, sonhamos com uma práxis educativa que valorize e dialogue com suas histórias, seus contextos, conhecimentos, experiências, indignações, crenças, de maneira democrática. Pela convivência tão próxima à categoria dos professores alfabetizadores, que trabalham junto às classes populares no interior da escola pública 
paulista, constatando a angústia e o desânimo que expressam nos dias atuais, acreditamos em uma ação cultural dialógica construída com eles, que os fortaleça politicamente e pedagogicamente para a luta coletiva.

Educadores e educadoras dedicados, especialmente, ao ensino público, carecem de oportunidades para redescobrirem-se como sujeitos históricos, conscientes de sua realidade e capazes de recriá-la. As reflexões que poderão estabelecer sobre sua existência, como pessoas, profissionais, cidadãos, na relação com o mundo e com os outros, poderão anunciar a possibilidade de escreverem suas próprias histórias e a história da escola pública.

Apesar da democratização do acesso aos bancos escolares, ainda encontramos um enorme contingente de estudantes das classes populares que, mesmo permanecendo no interior das instituições, não encontram condições favoráveis para avançarem em conhecimentos que os preparem para moverem-se socialmente.

No que se refere ao sistema público estadual de ensino de São Paulo, nos deparamos com a falta de investimento em todos os aspectos, e o descaso do poder político em relação à qualidade do serviço oferecido, manifestados na precariedade dos prédios e do material necessário ao trabalho pedagógico, na escassez de funcionários, na lotação das salas de aula (que inviabiliza a adequada atenção ao desempenho de todos/as), nas péssimas condições salariais e de carreira dos educadores, nas medidas assistencialistas e paliativas utilizadas para atender às reivindicações dos profissionais da educação e às necessidades da escola, retirando-lhes o valor e esvaziando-lhes de sentido. Quando os processos de avaliação externa apontam índices negativos em relação ao aproveitamento escolar dos estudantes, presenciamos a divulgação de discursos que depreciam as escolas e os educadores, culpabilizando-os unicamente pelo fracasso das iniciativas políticas empreendidas, como se estivessem desvinculados do funcionamento e da estrutura do sistema no qual trabalham.

Apesar das limitações impostas por este sistema, não descartamos a relação existente entre o desempenho dos estudantes e a formação e o trabalho dos educadores. Descartamos a visão focalista do problema, que atribui a responsabilidade pelo baixo desempenho dos estudantes apenas a uma parcela dos participantes deste sistema, isentando outros de seus compromissos, os quais agem, frequentemente, na imposição de entraves que tornam o processo educacional caótico, deficiente, empobrecido, apropriado ao atraso daqueles que mais precisam de suas contribuições. Não somos coniventes com a injustiça feita àqueles que, além de gente, são também cidadãos que pagam seus impostos e empenham maiores esforços para superarem os obstáculos sociais à sua humanização.

Compreendemos que é de fundamental importância revisar e analisar constantemente os currículos e os procedimentos pertinentes à educação dos 
educadores, tanto no âmbito da formação acadêmica como no âmbito da educação contínua, considerando, inclusive, a necessidade de se discutir com eles os inúmeros fatores que interferem em sua vida profissional, em sua rotina de trabalho, em seu desenvolvimento na carreira.

Acreditamos que o desvelamento da realidade que enfrentarão como futuros educadores, ou enfrentam como educadores em serviço, é tão relevante quanto a instrumentalização técnica. Temos a convicção de que não é mais possível prepará-los apenas para os desafios pedagógicos (o que também não ocorre ainda), mas para a consciência política, o posicionamento crítico frente às situações que envolvem a vida profissional, bem como a organização e o funcionamento do sistema educacional como um todo.

Nossos estudos, bem como a vivência do sistema público de educação, nos permite constatar que as transformações necessárias à melhoria da qualidade da educação e das condições de trabalho e escolarização, não se efetivam automaticamente pela "boa vontade" dos que detêm o poder. Ao contrário, são lutas nas quais todos precisam estar engajados, são sonhos a serem concretizados para a recuperação da dignidade e da valorização humanas, subtraídas daqueles que pertencem ao universo escolar, por meio de discursos e ações que invertem a posição dos indivíduos, de vítimas a culpados, imobilizando-os e atribuindo-lhes responsabilidades que são coletivas e que abrangem diferentes questões da área educacional.

Se defendemos a importância da educação dos educadores, não é possível omitir do processo formativo a necessidade da luta, o desenvolvimento da consciência política, o conhecimento amplo de nossa história e de nossa conformação social, imprescindíveis ao fortalecimento dos profissionais da educação, domesticados e manipulados pelas medidas legais e ideológicas. Esta luta, porém, não pode ser ensinada, mas aprendida e assumida em conjunto, com olhar direcionado a objetivos comuns, a situações e contextos que envolvem a todos, sejam estes formadores, gestores, acadêmicos ou professores.

Por toda a situação exposta, a vida e a produção de Paulo Freire nos orientam na reflexão e reconstrução das propostas para a educação contínua dos profissionais da educação, e em especial, neste trabalho, dos professores dos anos iniciais, que respondem pelo início da escolarização dos seres humanos e, portanto, são os mais atingidos pelas críticas sobre o despreparo dos estudantes para a continuidade dos estudos. Críticas que chegam dos representantes do poder político, dos meios de comunicação e dos próprios colegas de profissão.

Para que possam se assumir como seres humanos responsáveis, fazedores de sua história, é preciso que homens e mulheres aprendam a dizer sua palavra, pois, com ela constituem a si mesmos e aos outros, humanizam o mundo e se 
humanizam. Pela palavra, tomam este mundo como objeto e problema, questionamse sobre ele, refletindo-o ao se distanciarem dele, para nele estarem presentes.

Pelo distanciamento que faz do mundo, a consciência se constitui na objetividade e descobre-se em sua subjetividade. Portanto, consciência e mundo, subjetividade e objetividade são indicotomizáveis e implicam-se dialeticamente; “a verdadeira reflexão crítica origina-se e dialetiza-se na interioridade da 'práxis' constitutiva do mundo humano" (FREIRE, 2004, p. 15).

Considerando essa práxis humana, que explica os condicionamentos sofridos pelas pessoas, em suas relações no mundo, com o mundo e com os outros, bem como a capacidade de superação e transformação que têm manifestado historicamente, apresentamos as contribuições desta pesquisa à formação contínua dos professores e seus formadores, elaboradas por meio do diálogo entre pesquisadoras e sujeitos pesquisados, a partir da história de vida e formação destes sujeitos:

\section{A) Propostas à educação contínua no âmbito da escola}

- Construção do projeto político pedagógico da escola por meio da ação compartilhada e comprometida com o sucesso escolar dos estudantes, contemplando momentos de formação que ampliem as discussões sobre esse projeto e que considerem as relações família-escola;

- Articulação dialogada entre os educadores, os pesquisadores da universidade e a equipe técnica das Secretarias da Educação, por meio de grupos de discussão, buscando a ampliação e o aprofundamento de conhecimentos, a revisão dos currículos das licenciaturas e das ações implementadas pelas Diretorias de Ensino, estreitando relações entre a educação contínua dos diferentes educadores, sua formação inicial, o trabalho pedagógico das Diretorias e a realidade das escolas;

- Ampliação e diversificação das interações entre os profissionais do ensino e as famílias dos estudantes, buscando o debate dos problemas enfrentados, o planejamento de ações e a assunção conjunta do processo educativo, por meio do diálogo crítico que implica a confiança, a seriedade e a conduta ética para a melhoria do trabalho da escola;

- Realização de estudos que subsidiem o trabalho político e pedagógico das escolas, a partir da análise das ações empreendidas, problematizando-as e buscando conjuntamente novas formas de pensar e transformar o ensino e a vida profissional, considerando a leitura de mundo que os estudantes apresentam, o funcionamento e a organização dos sistemas de ensino, as políticas públicas.

\section{B) Propostas à educação contínua fora do contexto escolar}

- Estruturação de espaços dialógicos sobre a vida dos educadores e a vida nas escolas, sobre os sistemas de ensino e a prática pedagógica, por meio de gru- 
pos compostos por uma diversidade de pessoas que atuam em vários âmbitos do campo educacional: universidades, sindicatos, Diretorias de Ensino, Secretarias da Educação, estudantes, membros da comunidade, representantes de movimentos sociais, etc, visando a construção de novos olhares e meios de transformação do cenário educacional;

- Programação de encontros periódicos de formação dos formadores que se encontram nas unidades escolares - gestores e coordenadores pedagógicos - nas Diretorias de Ensino ou nas Secretarias Municipais de Educação, e nas universidades, visando o crescimento profissional de todos, por meio de estudos, diálogos, registros, reflexões sobre situações-problema e proposição de ações, vinculando a competência técnica ao compromisso político;

- Compartilhamento de conhecimentos e soma de esforços para o fortalecimento da categoria profissional dos educadores, reivindicando ao poder político a justa remuneração, que deverá envolver a atuação na escola e o envolvimento nas ações de formação coletiva, dentro e fora da instituição escolar, com o apoio de agentes universitários, líderes sindicais e representantes da comunidade, e garantindo a permanência dos profissionais nas escolas, a valorização dos mesmos, a melhoria da qualidade do ensino e a estruturação de um aparato legal que favoreça a construção de um plano de carreira mais digno.

Essas são algumas propostas elaboradas a partir das histórias dos sujeitos que estudamos, da práxis histórica de Paulo Freire e da Metodologia Comunicativo-Crítica, procurando destacar a dialogicidade na diversidade, a valorização e reflexão das contribuições dos diferentes agentes educativos para as discussões, decisões e transformações dos contextos educacionais e das pessoas que os fazem, considerando que a ação isolada de um agente sobre os outros pode provocar mudanças, mas não fortalece as relações para a luta.

\section{Referências}

ALMEIDA, M. I. Apontamentos a respeito da formação de professores. In: BARBOSA, R. L. L. (Org.). Formação de educadores. Artes e Técnicas - Ciências e Políticas. São Paulo: Editora UNESP, 2006. p. 178-188.

BORGES, A. S. Análise da formação continuada dos professores da rede pública de Ensino de São Paulo. In: MARIN, A. J. (Org.). Educação continuada. Campinas, SP: Papirus, 2004. p. 39-61.

CANDAU, V. M. Formação continuada de professores: tendências atuais. In: CANDAU, V. M. (Org.). Magistério. Construção cotidiana. Petrópolis, RJ: Vozes, 2001. p. 51-109.

ESTEVE, J. M. Mudanças sociais e formação docente. In: NÓVOA, A. (Org.). Profissão professor. Porto: Porto Editora, 1995. p. 93-124.

FREIRE, P. À sombra desta mangueira. São Paulo: Olho d’Água, 2005. 
FREIRE, P. Novos tempos, velhos problemas. In: SERBINO, R. V.; RIBEIRO, R.; BARBOSA, R. L. L.; GEBRAN, R. A. (Orgs.). Formação de professores. São Paulo: Editora UNESP, 1996. p. 37-43.

FREIRE, P. Pedagogia da Autonomia. SP: Paz e Terra, 1998.

FREIRE, P. Pedagogia do Oprimido. RJ: Paz e Terra, 2004.

FREIRE, P.; FAUNDEZ, A. Por uma Pedagogia da Pergunta. Rio de Janeiro: Paz e Terra, 2002.

FUSARI, J. C. Formação contínua de educadores na escola e em outras situações. In: BRUNO, E. B. G.; ALMEIDA, L. R. de.; CHRISTOV, L. H. da S. (Orgs.). O coordenador pedagógico e a formação docente. São Paulo: Loyola, 2000. p. 17-24.

GATTI, B. A.; BARRETO, E. S. de S. (Coord.). Professores do Brasil: impasses e desafios. Brasília: UNESCO, 2009.

GHEDIN, E. Implicações das reformas no ensino para a formação de professores. In: BARBOSA, R. L. L. (Org.). Trajetórias e perspectivas da formação de professores. São Paulo: Editora UNESP, 2004. p. 397-417.

GÓMEZ, J.; LATORRE, A.; SANCHEZ, M.; FLECHA, R. Metodologia Comunicativa Crítica. Barcelona/Espanha: El Roure Editorial, 2006.

MARIN, A. J. Educação continuada: introdução a uma análise de termos e concepções. Cadernos Cedes, Campinas, n. 36, p. 13-20, 1995.

MARIN, A. J. Propondo um novo paradigma para formar professores a partir das dificuldades e necessidades históricas nessa área. In: REALI, A. M. de M. R.; MIZUKAMI, M. da G. N. (Orgs.). Formação de professores: tendências atuais. São Carlos, SP: EdUFSCar, 2003. p. 153-165.

MIZUKAMI, M. da G. N. et al. Escola e aprendizagem da docência: processos de investigação e formação. São Carlos, SP: EdUFSCar, 2002.

TARDIF, M. Saberes docentes e formação profissional. Petrópolis, RJ: Vozes, 2004.

ZEICHNER, K. M. Formando professores reflexivos para a educação centrada no aluno: possibilidades e contradições. In: BARBOSA, R. L. L. (Org.). Formação de educadores: desafios e perspectivas. São Paulo: Editora UNESP, 2003. p. 35-55.

Recebido em 31/10/2014

Aceito em 19/06/2015 